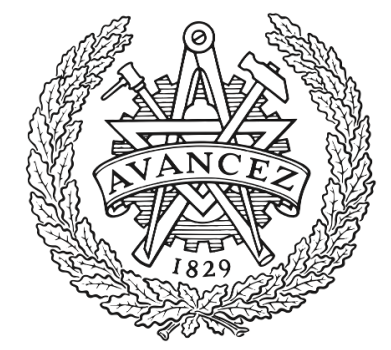

CHALMERS

UNIVERSITY OF TECHNOLOGY

\title{
Detailed Experimental Study of the Flow in a Turbine Rear Structure at Engine Realistic Flow Conditions
}

Downloaded from: https://research.chalmers.se, 2023-04-26 12:58 UTC

Citation for the original published paper (version of record):

Vikhorev, V., Chernoray, V., Thulin, O. et al (2020). Detailed Experimental Study of the Flow in a Turbine Rear Structure at Engine Realistic Flow Conditions. Proceedings of the ASME Turbo Expo, 2B. http://dx.doi.org/10.1115/GT2020-15734

N.B. When citing this work, cite the original published paper. 


\title{
DETAILED EXPERIMENTAL STUDY OF THE FLOW IN A TURBINE REAR STRUCTURE AT ENGINE REALISTIC FLOW CONDITIONS
}

\author{
Valentin Vikhorev ${ }^{1}$, Valery Chernoray ${ }^{1}$, Oskar Thulin², Srikanth Deshpande ${ }^{2}$, Jonas Larsson ${ }^{2}$ \\ ${ }^{1}$ Chalmers University of Technology, Gothenburg, SE-41296, Sweden \\ ${ }^{2}$ GKN Aerospace Engine Systems, Trollhättan, SE- 46181, Sweden
}

\section{ABSTRACT}

A good aerodynamic design of the turbine rear structure (TRS) is crucial for improving efficiency and reducing emissions from aero-engines. This paper presents a detailed experimental evaluation of an engine realistic TRS which was studied in an engine-realistic rig at Chalmers University of Technology, Sweden. The TRS test section was equipped with three types of outlet guide vanes $(O G V S)$ which are typical of modern state-ofthe-art TRS: regular vanes, thickened vanes and vanes with an engine mount recess (a shroud bump). Each of the three vane geometries were studied under on-design and off-design conditions at a fixed flow Reynolds number of 235,000. The study shows that the off-design performance of the TRS strongly depends on the presence of the local flow separation on the OGV suction side near the hub, which is greatly affected by the vane pressure distribution and inlet conditions. Similarly, the OGVs with increased thickness and with a vane shroud bump are shown to affect the performance of the TRS by influencing the losses on the OGV suction side near the hub. Furthermore, the presence of the bump is shown to have noticeable upstream influence on the outlet flow from the low-pressure turbine and noticeable downstream influence on the outlet flow from the TRS.

Keywords: low-pressure turbine, outlet guide vane, turbine rear structure, engine exit structure, turbine exhaust casing, tail bearing housing, turbine rear frame, exit guide vane, engine mount recess

\section{NOMENCLATURE}

$C_{p 0} \quad$ total pressure coefficient, $\left(P_{t}-P_{\text {tref }}\right) /\left(P_{\text {tref }}-P_{\text {sref }}\right)$

$C_{p} \quad$ static pressure coefficient, $\left(P_{\mathrm{s}}-P_{\text {sref }}\right) /\left(P_{\text {tref }}-P_{\text {sref }}\right)$

$H \quad$ channel height at inlet, $\mathrm{m}$

$P_{\mathrm{s}} \quad$ static pressure, $\mathrm{Pa}$

$P_{\mathrm{t}} \quad$ total pressure, $\mathrm{Pa}$

Re Reynolds number, $U_{x} H / v$

$V \quad$ blade velocity, $\mathrm{m} / \mathrm{s}$

$U_{x} \quad$ axial flow velocity, $\mathrm{m} / \mathrm{s}$

$x \quad$ streamwise coordinate, $\mathrm{m}$

$v \quad$ kinematic viscosity, $\mathrm{m}^{2} / \mathrm{s}$ $\varphi \quad$ flow coefficient, $U_{x} / V$

$\theta \quad$ angular coordinate, deg

$\begin{array}{ll}\text { ABBREVIATIONS } \\ \text { BPR } & \text { by-pass ratio } \\ \text { FC } & \text { flow coefficient } \\ \text { LPT } & \text { low pressure turbine } \\ \text { NGV } & \text { nozzle guide vane } \\ \text { OGV } & \text { outlet guide vane } \\ \text { TRS } & \text { turbine rear structure }\end{array}$

\section{INTRODUCTION}

Near-future demands for the reduced environmental impact of air transport has stimulated the innovation and improvement of the air engine design. The aerospace industry needs to meet the goals set by the Advisory Council for Aeronautics Research in Europe for the year 2050, where the main targets are a 75\% reduction in $\mathrm{CO}_{2}$ emissions, a $90 \%$ reduction in NOx emissions, and a $65 \%$ reduction of the perceived noise relative to engine and aircraft performance compared to values of the year 2000. In line with these requirements, increased bypass ratio (BPR) turbofan engines with ultra-high efficiency are currently under development. A prerequisite of the ultra-efficient engine design is careful aerodynamic and weight optimization of each engine component.

The larger fans of high-BPR engines require larger power and lower rotational speeds, which imposes new conditions on the aerodesign of the low-pressure turbine (LPT) and turbine rear structure (TRS). The TRS is a structural stator stage downstream of the LPT, which de-swirls the flow after the LPT to maximize engine thrust. The TRS consists of outlet guide vanes (OGVs) and a modern TRS includes several vane types: regular vanes, vanes equipped with an engine-mount recess (shroud bump), which serve a structural purpose, and vanes with increased thickness to allow for the passage of the bearing oil tubes.

In a traditional two- and three-spool engine the increased BPR results in a highly loaded LPT and large swirl angles out of the last LPT rotor. In a geared engine with a high-speed turbine 
decoupled from the fan the outlet swirl angle from the turbine rotor is less problematic. However, the off-design variations of the outlet swirl angle increase substantially. Both factors make the aerodynamic design of a modern TRS more demanding and a robust TRS design that performs well for all engine operating points is therefore particularly challenging.

The flow in the TRS is highly diffusive with the interaction between the boundary layers of the OGVs with the boundary layers of the hub and shroud and with a swirled unsteady incoming flow from the LPT. The interacting decelerated boundary layers in combination with the adverse pressure gradient lead to local flow separations. The prediction of these flow separations is particularly challenging since the boundary layers on OGVs undergo laminar-turbulent transition. Both the laminar-turbulent transition and flow separation are challenging for numerical predictions using computational fluid dynamics (CFD) simulations. Therefore, detailed experimental aerodynamic and heat-transfer studies of the TRS under ondesign and off-design conditions are required.

The first detailed aerodynamic studies of OGVs were made in a linear LPT-OGV cascade, representing a two-dimensional approximation of vanes without a curvature effect, radial pressure gradient and unsteady turbine wakes. A significant contribution to the research field was made by Hjärne et al. [1$3]$. Besides the experimental results for on- and off-design conditions, these studies presented validation of numerical simulations. In further works by Hjärne et al. $[4,5]$ detailed investigation of the secondary flows and loss development was performed experimentally and numerically noting the effect of the free-stream turbulence and inlet boundary layer thickness on the secondary flows. The study of the TRS in an annular rig with an unshrouded turbine was performed by Selic et al. [6]. This work highlighted the effect of the turbine tip clearan ce on the losses and the importance of an engine realistic LPT stage. Further investigations in a newly established TRS facility at Chalmers University of Technology [7-9] were carried out in a rig equipped with a realistic shrouded LPT and operated at engine-realistic flow Reynolds numbers. The design of the new rig is presented by Rojo et al. [7]. Jonsson et al. [8] presented the accurate measurements of the heat transfer coefficient on OGVs, which has allowed for the mapping of the laminar-turbulent transition on OGVs for a number of aerodynamic load cases and his work is further extended and compared to CFD in an accompanying paper [10]. Jonsson et al. [9] illustrated the impact of surface roughness on secondary flows and pressure losses in a TRS. Both studies [8,9] highlighted the significance of the laminar-turbulent transition on the performance of the TRS.

The studies [7-9] were performed for TRS consisting of 12 so-called regular vanes, however a typical modern TRS design includes several ( 2 or more) vanes equipped with an engine mount recess (also called a shroud bump) and several (typically 2-3) thickened vanes. The role of the engine mount recess is to structurally enforce the TRS at the attachment points of the engine to the aircraft. The role of the thickened vanes is to provide space for oil tubes lubricating the rear engine bearings.
The influence of the bump vane was previously studied in a linear cascade [11], but neither the bump nor the thickened vane have previously been studied in an annular rig with an upstream LPT. The aim of the current study is to investigate the performance of a realistic TRS with the implementation of the thick and bump vane under on- and off-design conditions.

\section{EXPERIMENTAL DETAILS}

Experimental investigations were carried out in a closedcircuit low-speed large-scale 1.5 stage LPT-OGV facility at Chalmers University of Technology, Sweden. Figure 1 presents the schematic diagram of the facility. Operating conditions for the TRS that can be achieved in the rig are realistic for up to large turbofan engines with a Reynolds numbers of up to 435,000 and above. The airflow is driven by a $250-\mathrm{kW}$ centrifugal fan. The flow from the centrifugal fan passes through diffusers and corner ducts, which are equipped with turning vanes, and enters the settling chamber containing a honeycomb and five dampening screens of different sizes, from larger to smaller size meshes. The settling chamber enables uniform flow into the contraction and reduces the turbulence level. The steady temperature of the flow is maintained by a heat exchanger enabling steady flow conditions in the rig with good repeatability.

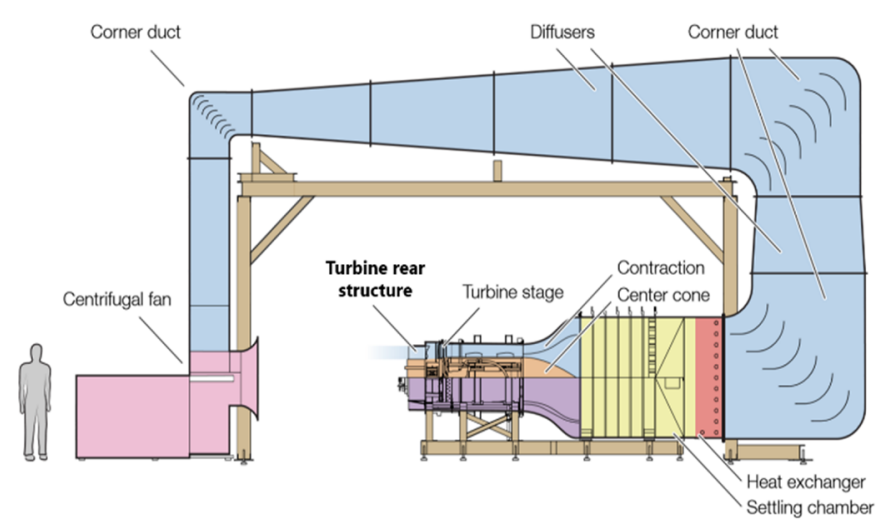

FIGURE 1: Section view of the LPT-OGV facility (from Jonsson et al. [8])

The LPT stage consists of a stator stage with 60 nozzle guide vanes (NGVs) and a shrouded rotor stage with 72 blades, and is a research LPT geometry designed by GKN Aerospace Engine Systems, Sweden. The LPT stage provides realistic inlet boundary conditions for the TRS section. The TRS includes 12 OGVs which are positioned with a 30-degree spacing. A hydraulic brake on the turbine's rotor shaft provides a wellcontrolled load for the turbine. The turbine braking torque and the axial velocity in the test section are controlled in order to obtain constant values of the flow Reynolds number and the flow coefficient (FC), defined as the ratio of the axial velocity to the blade speed:

$$
\varphi=U_{x} / V
$$

Further details of the facility design can be found in Ref. [7]. 
The TRS section is equipped with two internal traversing systems working independently, moving radially and circumferentially. The traversing system located downstream of the TRS has an additional axial stage enabling a probe to be positioned at any point within the TRS. The traversing systems are fully automated and controlled by a PC with in-house LabVIEW $^{\circledR}$ (National Instruments Corporation, Austin, TX, USA) software scripts. The positioning accuracy in the circumferential directions is $0.01^{\circ}$ and in the radial and axial directions $0.075 \mathrm{~mm}$.

Total pressure and swirl measurements are performed using pre-calibrated 5-hole and 7-hole aero probes on two planes, one located upstream (Inlet plane) and one downstream (Outlet plane), see Fig. 2. Static pressure measurements on the vane and shroud bump were taken with the help of two Scanivalve mechanical multiplexers with 48 ports each. The pressures from the multi-hole pressure probes and Scanivalve multiplexers are acquired using a 16-channel PSI-9116 system with a $500 \mathrm{~Hz}$ sampling rate and 2.5 seconds sampling time.

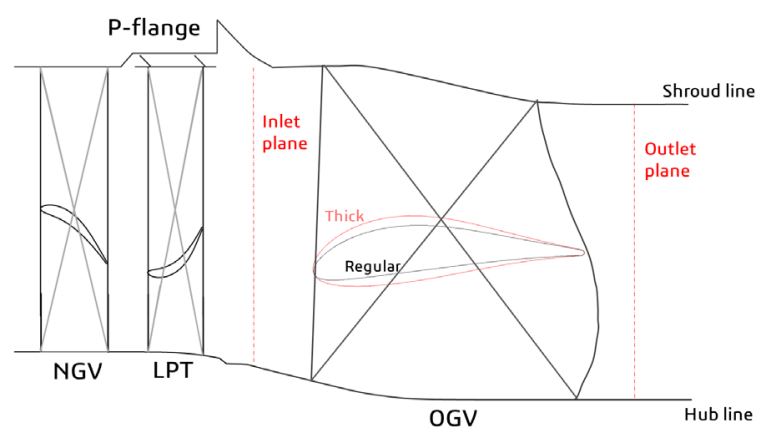

FIGURE 2: Meridional view of turbine stage and test section, illustrating measurement planes and mid-span blade profiles

The total and static pressure data are presented in the form of non-dimensional coefficients (Eq. 2 and 3). The reference values are measured by a stationary Prandtl tube located in the bulk flow region between OGVs at 0.7 chord distance from the leading edge.

$$
\begin{gathered}
C_{p 0}=\frac{P_{\mathrm{t}}-P_{\text {tref }}}{P_{\text {tref }}-P_{\text {sref }}} \\
C_{p}=\frac{P_{\mathrm{s}}-P_{\text {sref }}}{P_{\text {tref }}-P_{\text {sref }}}
\end{gathered}
$$

Tests are carried out under on-design and off-design conditions. The flow Reynolds number based on inlet channel height, is 235,000 , which is used for all three operation points. The TRS inlet conditions are summarized in Table 1 where the flow coefficient values are presented with their corresponding averaged LPT exit swirl angles.

Tests are performed for three types of TRS vanes: a regular vane, a thick tube vane, and a vane equipped with an enginemount bump. It shall be noted that the LPT and TRS components have been designed solely for the experimental rig and are not related to any GKN Aerospace product characteristics. For the regular vane configuration, the test section was equipped with 12 regular vanes, for two other configurations the test section was equipped with three modified vanes and nine regular vanes. The measurements were performed on the mid-vane of three modified vanes.

\begin{tabular}{|c|c|c|c|}
\hline $\begin{array}{l}\text { Operating } \\
\text { Condition }\end{array}$ & $\begin{array}{c}\text { Flow } \\
\text { coefficient, } \\
\varphi\end{array}$ & $\begin{array}{l}\text { Inlet swirl } \\
\text { angle, deg }\end{array}$ & $\mathrm{Re}$ \\
\hline On-design & 0.622 & -16.5 & \multirow{4}{*}{235000} \\
\hline $\begin{array}{l}\text { Off-design } \\
\text { (Low loading) }\end{array}$ & 0.588 & -11.5 & \\
\hline $\begin{array}{l}\text { Off-design } \\
\text { (High loading) }\end{array}$ & 0.657 & -20.9 & \\
\hline $\begin{array}{l}\text { Off-design } \\
\text { (High loading) }\end{array}$ & 0.775 & -31.6 & \\
\hline
\end{tabular}

TABLE 1. Inlet conditions

\subsection{Thick vane}

The requirement of allowing oil pipelines to pass through OGVs leads to increased thickness of the OGVs. A dedicated tube vane (research configuration) with enlarged thickness was designed by GKN Aerospace Engine Systems. Compared to the regular research OGV, the mid-span airfoil section of the thick OGV has an increased thickness by $45 \%$ (Fig. 2) while the camber line is maintained the same.

Figure 3 depicts a 3D model of a thick vane manufactured with SLA (stereolithography) rapid prototyping method.

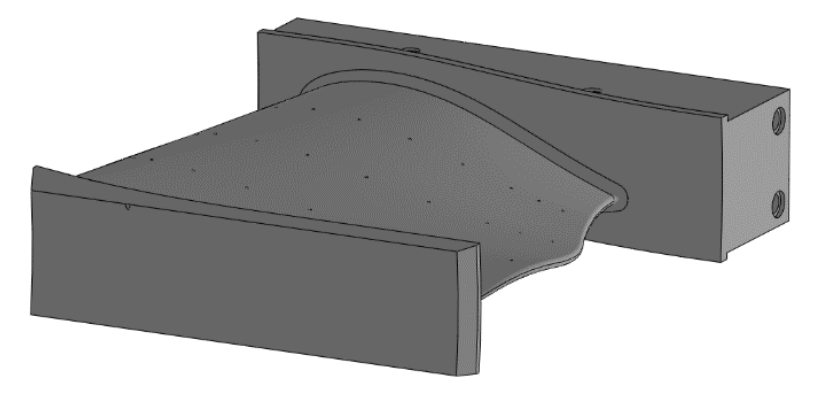

FIGURE 3: A 3D model of a thick OGV (so-called tube OGV) with implemented pressure taps

Three thick vanes were implemented in the rig to reflect conditions in a real aero engine. The aerodynamic performance of the vanes was evaluated according to the measurement of total pressure and flow angles at Inlet and Outlet planes. The static pressure distribution on the vane was monitored via pressure taps with a diameter of $0.7 \mathrm{~mm}$ which were embedded in the OGVs. The static pressures were measured at five spans on the vane: at 
$12.5,25,50,75$ and $87.5 \%$. Two instrumented vanes were manufactured, one equipped with pressure taps at 12.5, 50 and $87.5 \%$ spans and one equipped with pressure taps at 25, 50 and $75 \%$ spans. Figure 3 shows one of the vanes. These vanes were swapped one-by-one in the location of the measurement vane. The mid-span pressure taps were present on both vanes and were used to check the repeatability of the measurements.

\subsection{Bump vane}

The engine mounts by which the aero-engine is mounted to the aircraft are attached to the TRS. To reduce induced bending moments, a structural engine mount recess is provided on the TRS shroud, where the engine mounts are attached. The engine mount recess results in a bump protruding into the gas path of the TRS.

A research configuration of the $\mathrm{OGV}$ with an engine-mount bump on the shroud was designed by GKN Aerospace Engine Systems. Figure 4 shows a 3D model of the studied bump vane.

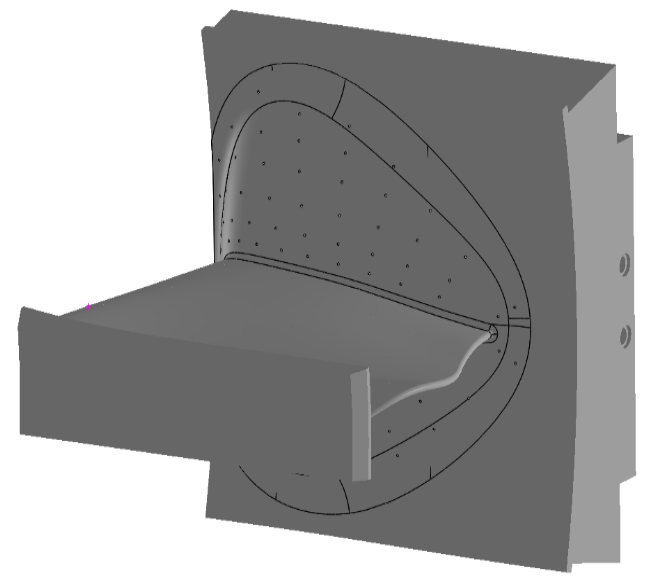

FIGURE 4: A 3D model of the OGV with an engine-mount recess (bump) and implemented pressure taps on the bump surface

Three vanes with engine-mount bumps were implemented in the rig to reflect conditions in an aero-engine. A mid-vane of the three vanes was equipped with pressure taps on the vane and on the bump. The two other bump OGVs were made from regular OGVs by adding bump modifications to the shroud. The pressure taps on the vane surface were positioned along three spans $(25$, 50 and $75 \%$ ) and distribution of the pressure taps on the bump surface is shown in Fig. 4. The bump surface was equipped with 96 pressure taps.

\section{RESULTS AND DISCUSSION}

The experimental results are presented in four subsections according to the type of data. The emphasis of this article is on the comparison of the aerodynamic performance of the thick vane and bump vane with the regular vane. Thorough aerodynamic studies as well as numerical investigation of the TRS with regular vanes are presented in Refs. [8, 9, 12].

\subsection{Flow visualizations}

The objective of this section is to highlight the flow behavior around the OGV for different operating conditions. An oil-film visualization of the OGV suction side was carried out to visualize the near-wall streamlines and flow separations. The thick OGV oil-visualizations are presented in this paper. Similar visualizations for the regular $\mathrm{OGV}$ can be found in an accompanying paper [10].

The visualizations were performed by the oil-film method. A mixture of kerosene, mineral oil and $\mathrm{TiO}_{2}$ powder, with particles from 0.2 to $0.3 \mu \mathrm{m}$ was used.

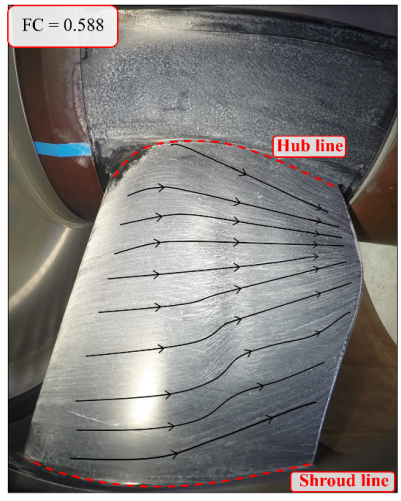

a) Surface oil visualization at $\mathrm{FC}=0.588$

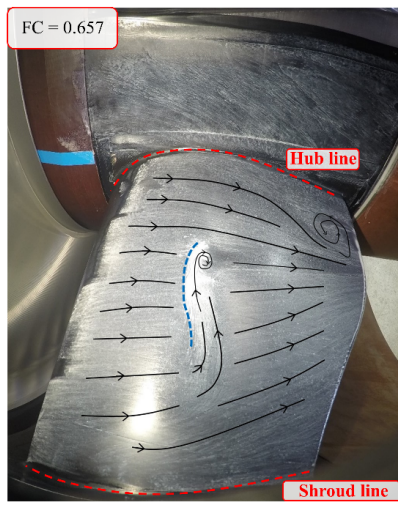

c) Surface oil visualization at $\mathrm{FC}=0.657$

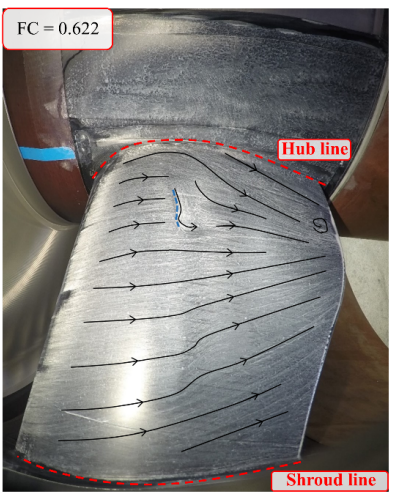

b) Surface oil visualization at $\mathrm{FC}=0.622$

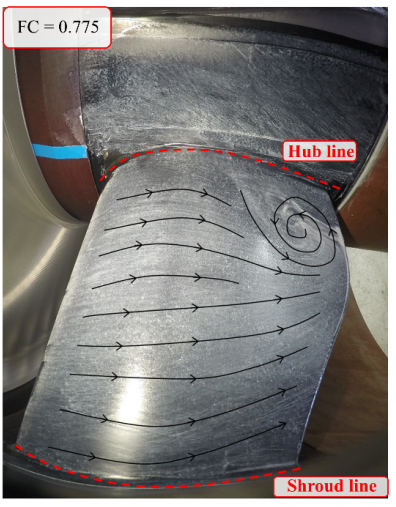

d) Surface oil visualization at $\mathrm{FC}=0.775$
FIGURE 5: Oil-film visualizations on a thick OGV suction side at on-design flow coefficient (0.622) and three off-design flow coefficients $(0.588,0.657,0.775)$

The visualizations (Fig. 5) demonstrate clear changes in the surface streamlines with changes of the flow coefficient. In all shown cases, one can observe that the flow on the vane near the hub and shroud migrates towards mid-span, which creates two deceleration zones in the end-wall regions due to the area expansion of the stream tubes. At minimal OGV load (see Fig. 5a at the off-design flow coefficient 0.588) the near-wall streamlines are smooth without any indication of flow separation. For the on-design condition (Fig. 5b) a small region with accumulated particles is clearly visible at the OGV trailing edge near the hub, indicating a very small local separation bubble 
with reattachment. This is most likely caused by the secondary flows from the hub migrating up along the vane suction side. Furthermore, a streamline deviation in the design-point with flow coefficient 0.622 , marked with blue dashes in Fig. 5b, is visible near the hub at $25 \%$ span and approximately $40 \%$ chord. The authors believe that this is caused by a local laminar separation bubble followed by transition and turbulent reattachment. The flow deceleration near the hub increases at increased vane loads (see Figs. $5 \mathrm{c}-\mathrm{d}$ at the off-design flow coefficients 0.657 and 0.775 , respectively). A growing region with reversed flow near the OGV trailing edge close to the hub is formed as the load increases. At the off-design case with flow coefficient 0.657 ( $5^{\circ}$ higher absolute swirl), shown in Fig. 5c, there is a mid-span region with accumulated oil particles at $\sim 40 \%$ chord, highlighted by a blue dashed line. This region disappears at increased vane load in Fig. 5d. It was found that the formation of this region is very sensitive to the oil-film thickness, which indicates that a laminar flow separation with further turbulent reattachment may take place. The accompanying study [10] shows that on the regular vane the laminar-turbulent transition of the boundary layer takes place in this location and that the transition occurs at strong negative values of the acceleration parameter close to the separation margin.

\subsection{Pressure load distribution on the vanes and bump}

Figure 6 presents static pressure coefficients for the regular and thick vanes at on-design condition for 25,50 , and $75 \%$ spans.

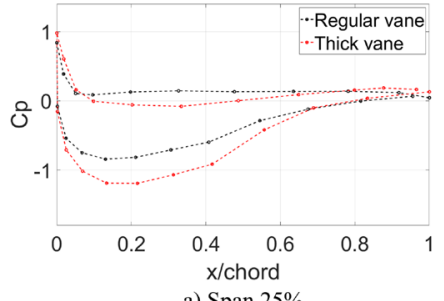

a) Span $25 \%$

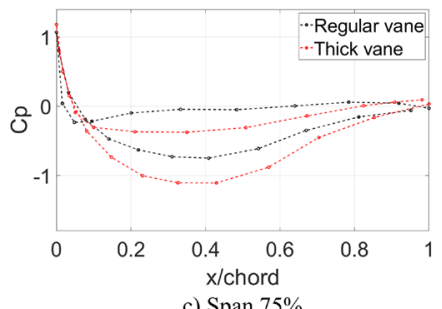

c) Span $75 \%$

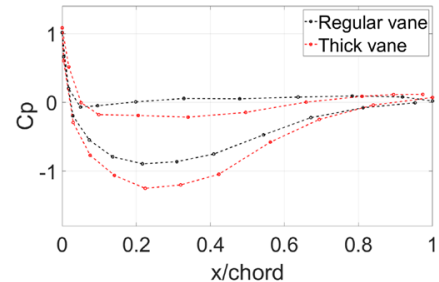

b) Span $50 \%$
FIGURE 6: Static pressure coefficient distributions at 25, 50 and $75 \%$ spans for the regular and thick vanes at on-design flow coefficient

The thick vane has a larger blockage than the regular vane. This yields increased acceleration and lower static pressures both on the suction side and on the pressure side. This can be seen on all spans in Fig. 6. The minimum pressure, on the more critical suction side, is reduced for the thick vane. This increases the diffusion and makes the thick vane more sensitive to separation problems. The axial position of the suction minimum doesn't change notably between the regular and the thick vanes.

For both vanes, however, the suction peak moves downstream as the span increases. Since both vanes have been designed with similar camber-lines and scaled thickness distributions this similarity is expected. A kink can be observed at approximately $40 \%$ chord which typically indicates a laminar flow separation. The location of this kink is consistent with the flow visualization results (Fig. 5b).

The pressure load of the thick vane, when compared to the regular vane, obviously increases at all spanwise locations. The pressure load is characterized by the area restricted between the pressure side and the suction side curves according to the pressure force definition. As known from the force balance in the two-dimensional cascade theory the lift force on the vanes is coupled with the flow turning through the cascade, however, this is not necessarily the case for $3 \mathrm{D}$ vanes due to the spanwise flow redistribution.

Figure 7 presents a comparison of the static pressure coefficient distributions for the regular and bump vanes at ondesign condition for 25,50 and $75 \%$ spans. Notably, for 25 and $50 \%$ spans the vane load change is minor. A slight pressure coefficient decrease is observed which can be explained by the presence of a bump as a blockage to the passing flow. However, for the spanwise location near the shroud (75\% span), which is located closest to the bump, the changes are significant, due to the promoted acceleration of the flow in the front part of the bump and promoted deceleration in the rear part of the bump. As a result, the suction-side pressure peak on the vane near the bump (75\% span) is moved upstream.

A side-by-side comparison of the pressure distributions for the thick vane and the bump vane in Figs. 6-7 shows that the near-hub region at $25 \%$ span and the mid-span region at $50 \%$ span are affected more by the increased vane thickness than by the bump.

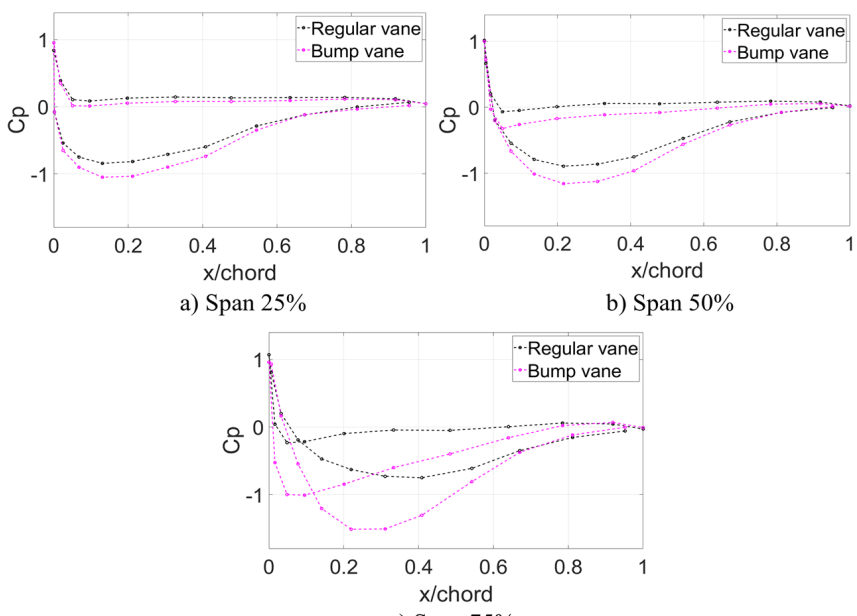

c) Span $75 \%$

FIGURE 7: Static pressure coefficient distributions at 25, 50 and $75 \%$ spans for the regular and bump vanes at on-design flow coefficient 
Figure 8 presents the static pressure coefficient distributions on the bump surface under on-design conditions. Fig. 8a shows the data at actual measurement points and Fig. $8 \mathrm{~b}$ shows the interpolated data.

There is a high-pressure region in front of the bump caused by the flow stagnation, which is followed by a low-pressure region in the region of the maximum bump thickness. The bump pressure distribution interacts with the vane pressure distribution resulting in the negative pressure on both vane sides, which also explains the pressure distribution of Fig. 7c. The pressure minimum on the vane suction side is located at $25 \%$ chord and on the vane pressure side at $10 \%$ chord.
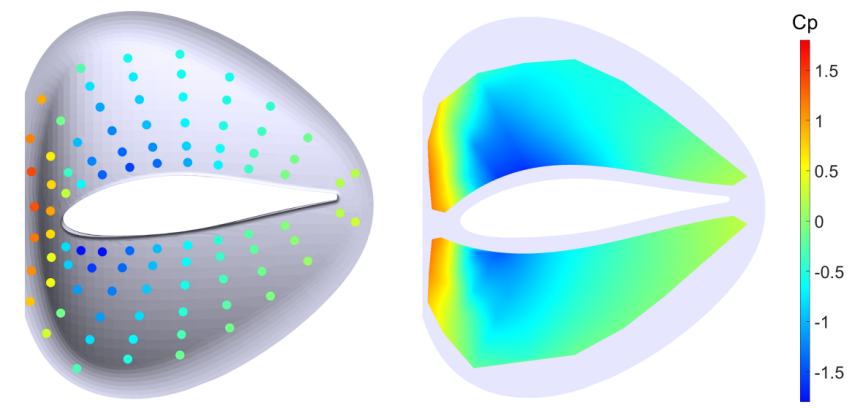

a) Cp distribution for the bump

b) Interpolated $\mathrm{Cp}$ values for the bump

FIGURE 8: Static pressure coefficient distributions on the bump at on-design flow coefficient

The pressure distributions on the bump at other inlet swirl angles did not show a notable difference. The pressure distributions on the bump do not indicate any flow separation on the bump, which points to a good aerodynamic performance for the current aerodesign of the bump itself.

The distributions of the static pressure coefficient at midspan for the regular, thick and bump vanes at all three operational points are presented in Fig 9.
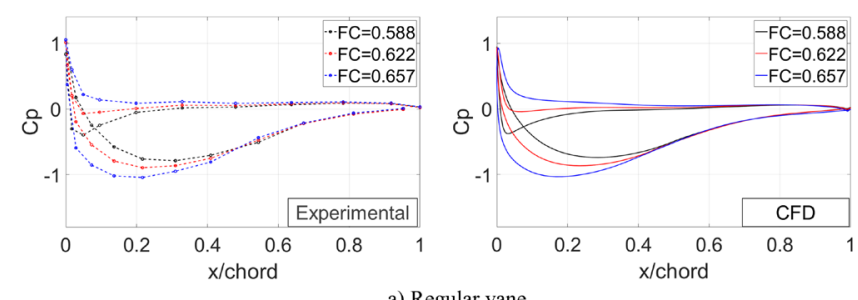

a) Regular vane

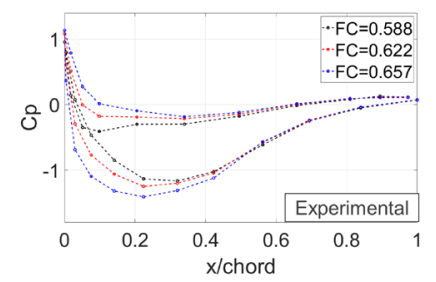

b) Thick vane

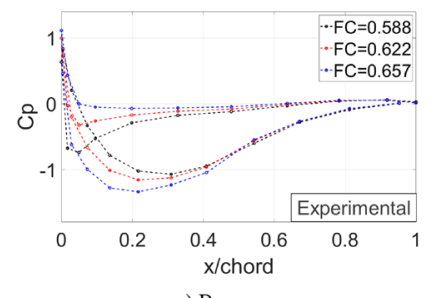

c) Bump vane
FIGURE 9: Static pressure coefficient distributions at mid-span of the regular, thick, and bump vanes under on- and off-design flow coefficients
The change of the flow coefficient leads to a notable change of the vane load, as expected. The increase of the flow coefficient for all vane types moves the minimum pressure point on the suction side toward the leading edge. In addition, with the increase of the vane load, a kink appears in the deceleration region at the suction side, at $\sim 40 \%$ chord, which indicates the presence of a local laminar flow separation followed by transition and reattachment for all three vane types.

To summarize all static pressure data, contours of the static pressure coefficient on the suction side of the regular, thick and bump vanes at on- and off-design conditions are presented in Fig. 10. For the thick vane, the data shows extra spans, which were not shown previously, close to the hub at $12.5 \%$ span and close to the shroud at $87.5 \%$ span.

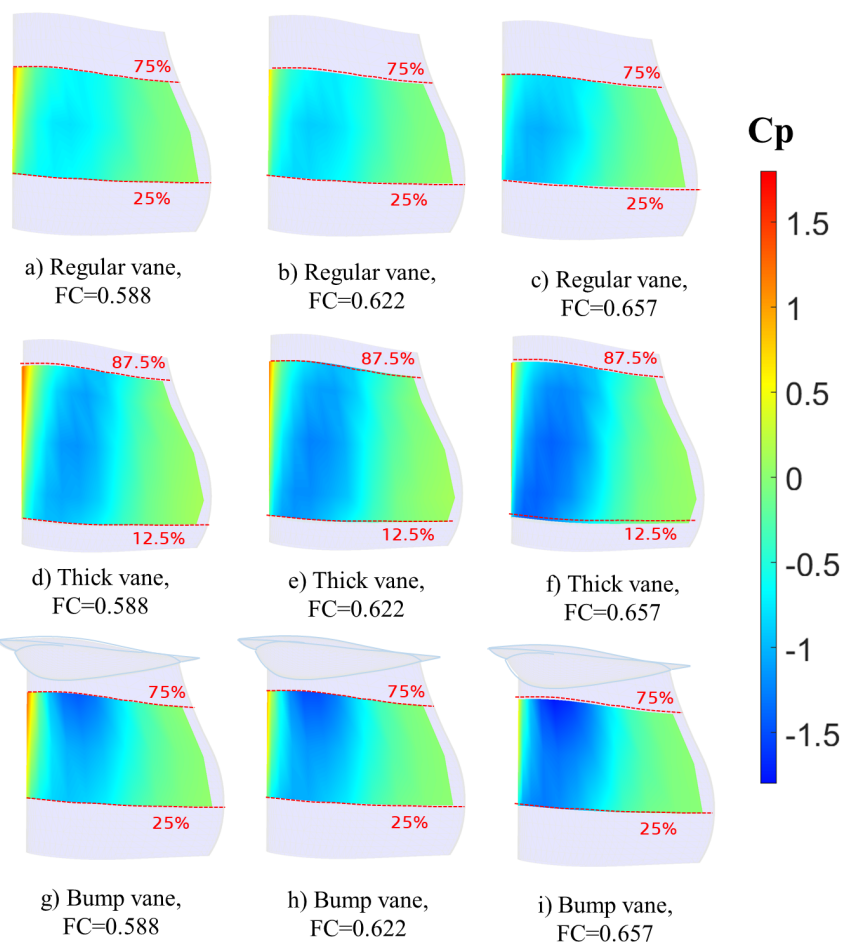

FIGURE 10: Contours of static pressure coefficient on the suction side of the regular, thick and bump vanes at on- and offdesign flow coefficients

The static pressure contours once more illustrate that the vane thickening affects the pressure along the entire OGV span while the bump, as expected, has the largest effect near the shroud. The effect then gradually decreases toward the hub. Furthermore, the pressure distributions show that both thick and bump vanes are robust and handle off-design angles well. The position of the stagnation point does not change for the different vane types.

\subsection{Inlet and outlet measurements}

This section presents the total pressure and swirl angle measurements at the inlet and outlet of the TRS. The 
measurements were performed in 30-degree sectors upstream and downstream of the OGV.

Figure 11 presents the total pressure coefficient distributions at the inlet plane for all three vane configurations at the ondesign point. The streamlines in the figure show the crossflow velocity components.

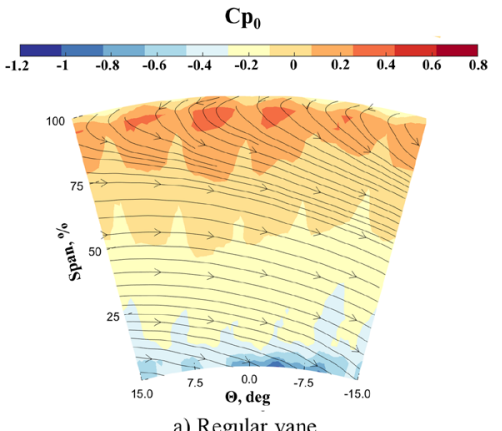

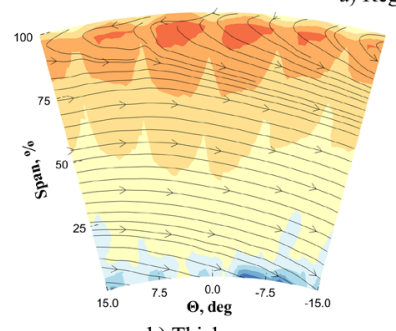

b) Thick vane

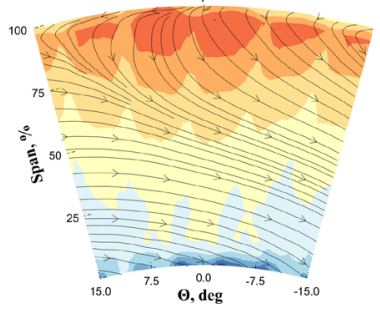

c) Bump vane
FIGURE 11: Total pressure coefficient distributions at Inlet plane for regular, thick, and bump vanes at on-design flow coefficient

Traces of stator wakes can be seen for all three vane types in Fig 11. These wakes originate from the NGV's upstream of the LPT rotor. Further, the local total pressure drop regions near the hub should be noted. These local loss regions originate from secondary flow vortices from the NGVs. Further details of their origin can be found in Ref. [12]

Figure 12 shows the inlet circumferentially averaged swirl and total pressure coefficient profiles for the different vanes under on-design and two off-design conditions.

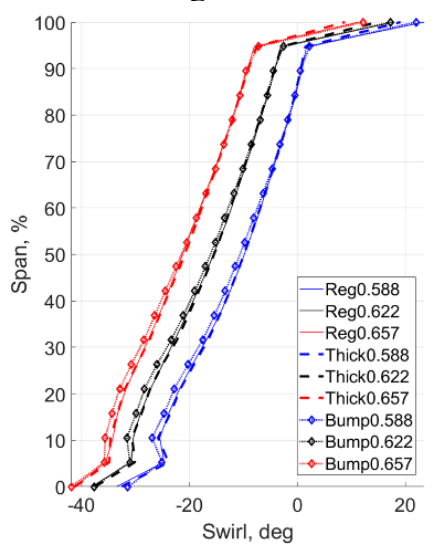

a)

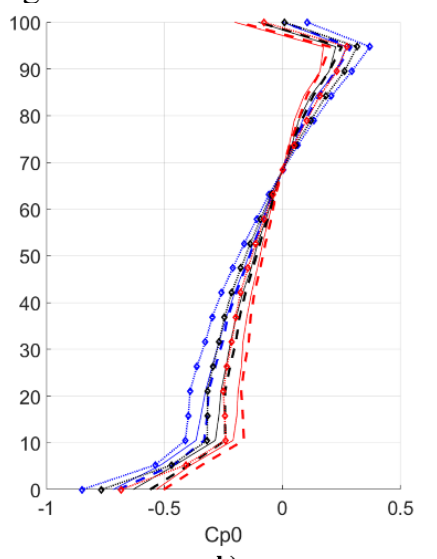

b)
FIGURE 12: Circumferentially averaged inlet swirl angle and total pressure coefficient for the regular, thick and bump vanes at on- and off-design flow coefficients
An interesting observation is that there is an inlet swirl variation across the channel.

The flow swirl on the vane is the largest (the absolute value of swirl angle is the largest) near the hub and decreases near the shroud where it reaches to zero and positive swirl angle. As a result, the vane load is the largest near the hub. Notably, in comparison with other cases the inlet swirl angle for the bump vane case decreases near the hub (thus, the load increases) due to the upstream influence of the bump vane (Fig. 12a). The inlet total pressure profile (Fig. 12b) is skewed as well, with the lowest total pressure near the hub and the largest in the shroud region. Importantly, with the increase of the flow coefficient the skewness of the total pressure profile decreases. For different vane cases, the total pressure profile skewness changes as well, with the thick vane case having the least skewed profile and the bump vane case having the most skewed profile.

Figure 13 shows the comparison of the total pressure coefficient for the regular, thick and bump vanes at on-design and two off-design points at the outlet of the TRS.

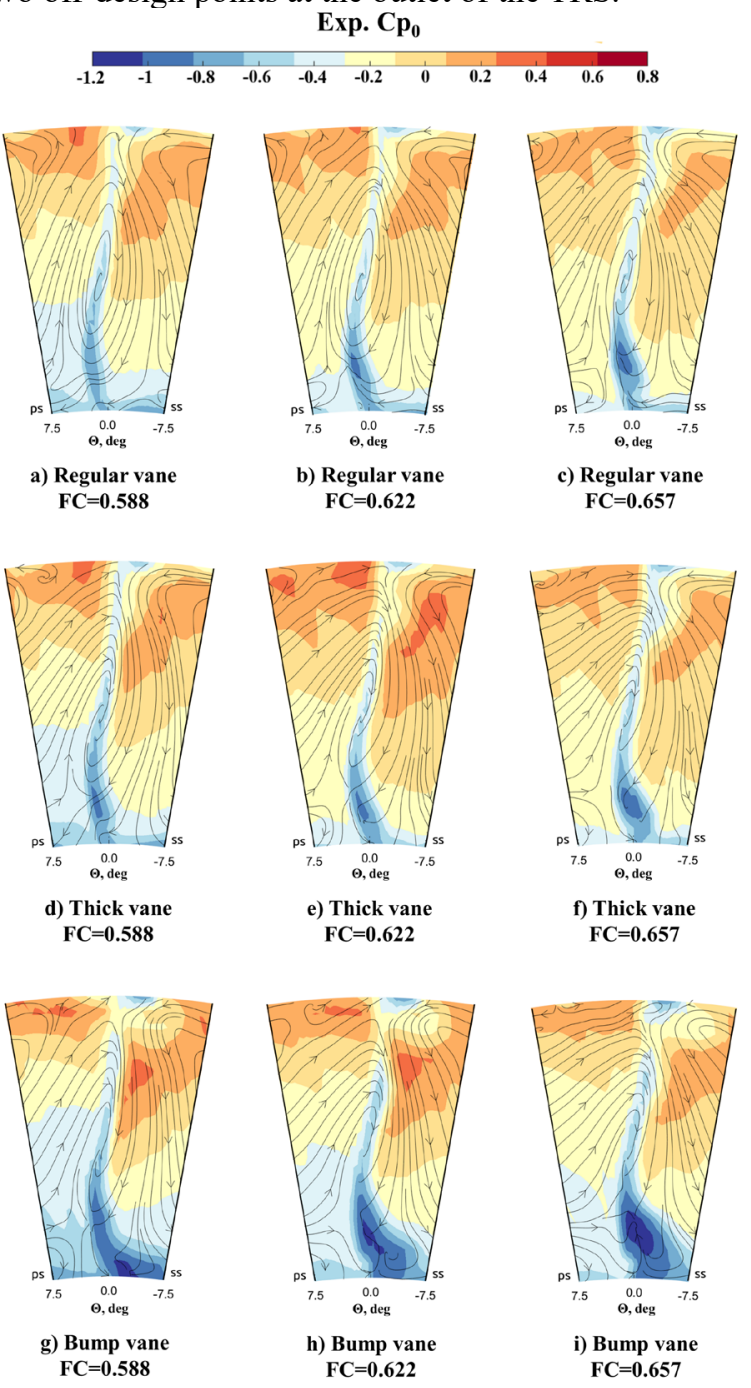

FIGURE 13: Wake comparison for regular, thick and bump vanes at on- and off-design flow coefficients 
a) Regular vane $\mathrm{FC}=\mathbf{0 . 5 8 8}$

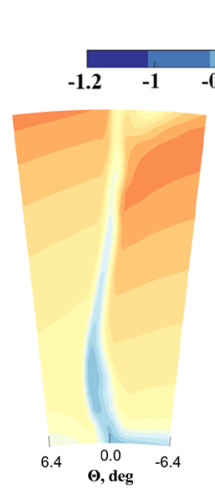

CFD Cp $\mathbf{p}_{0}$

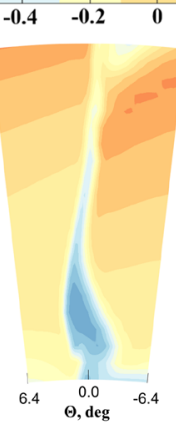

b) Regular vane $\mathrm{FC}=\mathbf{0 . 6 2 2}$

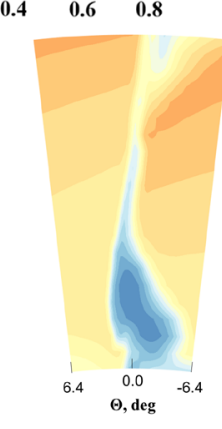

c) Regular vane $\mathrm{FC}=\mathbf{0 . 6 5 7}$
FIGURE 14: CFD wakes for regular vane at on- and off-design flow coefficients

As seen, the shape and intensity of the wake for the thick vane is similar to the regular vane, which suggests that the mechanisms for the loss formation are similar for these two vanes. As the flow visualizations of Fig. 5 show, the flow from the endwalls on the suction side of the vane is directed towards the midspan, due to the combined effect of the endwalls and the pressure gradient in the cascade between the pressure and the suction sides [13]. Since the load of the OGV is the largest near the hub and the total pressure is the lowest, a region with the lowest total pressure is formed from the OGV suction side near the hub. The endwall influence near the shroud also leads to the formation of a low total pressure region, which is less pronounced since the inlet total pressure is larger near the shroud and the vane load is smaller. The thickening of the vane leads to a slight increase in losses in the near-hub region (Fig. 13, d-f).

The presence of the bump on the OGV is notably redistributing the total pressure in the shroud region. Further, the total pressure near the hub is visibly larger due to the more skewed inlet total pressure profile. Moreover, the region with the increased losses near the shroud is moved from the OGV wake towards the shroud, due to the action of the bump. Additionally, it is seen that at flow coefficient 0.588 , the losses in the OGV wake are very similar to the regular and thick vane cases, however there is an additional region with the increased pressure loss created near the hub, which indicates a possible flow separation on the hub wall due to the extra adverse streamwise pressure gradient induced by the bump. At increased flow coefficient this region increases and merges with the high-loss region on the vane suction side near the hub, creating a common loss region. The total pressure losses are visibly larger in this region when compared to the regular and thick vane cases.

Figure 15 shows the circumferentially averaged downstream profiles of the swirl and total pressure for the different vanes under on-design and two off-design conditions. Fig. 15a shows that the regular and thick vanes have very similar outlet swirl profiles. Both vanes are over-turning the flow at flow coefficient 0.588 , when the vane load is larger, compared to the on-design case of 0.622 , and under-turning the flow at flow coefficient
0.657 . The underturning and overturning are less than by one degree as aimed by the vane design. For the bump vane, the flow turning is visibly increased in the hub region and decreased in the shroud region. Fig. $15 b$ shows that near the hub the losses are the largest at flow coefficient 0.657 and the smallest at flow coefficient 0.588 . The regular vane and the thick vane have very similar losses, but the bump vane shows substantially increased losses in the hub region.

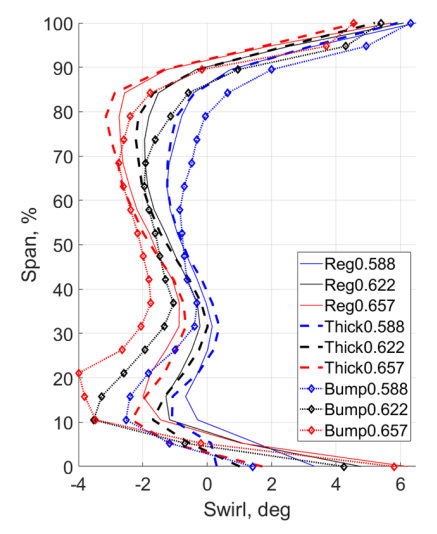

a)

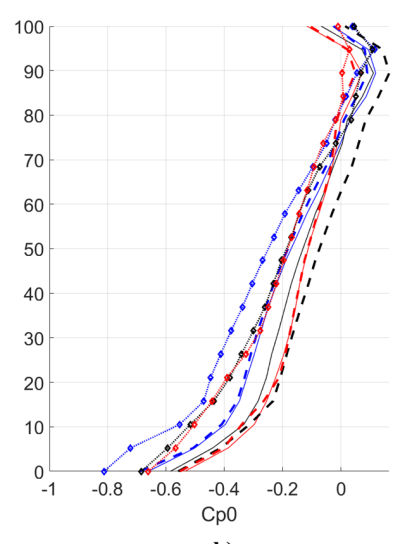

b)
FIGURE 15: Circumferentially averaged outlet swirl angle and total pressure coefficient for the regular, thick and bump vanes at on- and off-design flow coefficients

\subsection{Comparison of outlet wake profiles}

Figure 16 presents the total pressure coefficient for the thick and bump vanes in the spanwise locations near the hub compared to the regular vane at on-design point.

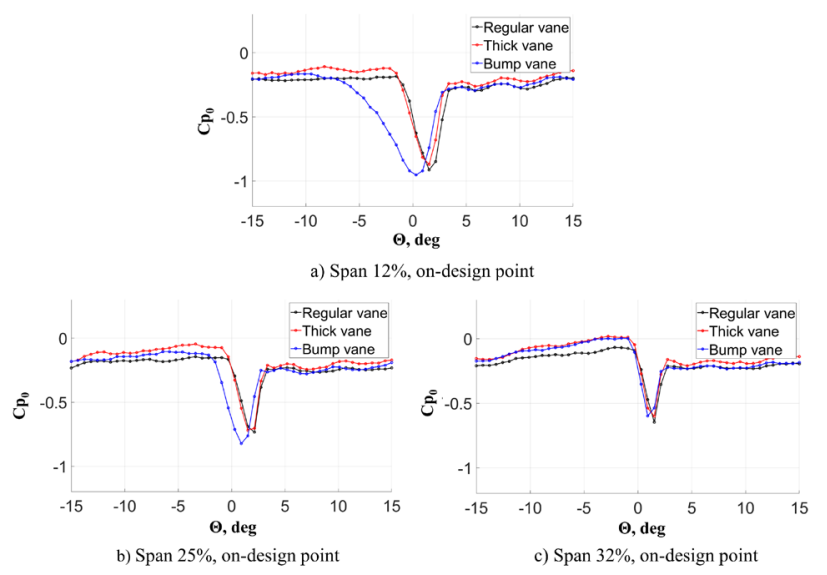

FIGURE 16: Total pressure coefficient distributions for 12, 25, and $32 \%$ spans for the regular, thick and bump vanes at ondesign flow coefficient

As can be seen from the wake profile of the thick vane, a change in the blade thickness does not lead to a change in the pressure loss. This supports the previous conclusions that the thickening of the vane does not affect the flow in terms of the aerodynamic performance for the on-design case compared to the regular vane. 
Significant changes in the wake thickness are seen for the bump vane case. As the presented profiles show, the wake thickness and depth are significantly increased at the span closest to the hub (12\%). At $25 \%$ span, the increase is less and at $32 \%$ span, the wakes are nearly identical in strength.

Figure 17 shows the wake profiles at different spans for the two off-design cases. These results demonstrate that for the thick vane the flow becomes more sensitive in the hub region for decreased values of the flow coefficient. This translates to the enlargement of the wake depth. For both off-design flow coefficients at $12 \%$ span, the wake increases about twice for the bump vane compared to the regular and thick vanes. At $25 \%$ span, the wake increase is less and at $32 \%$ span, the wake increase is negligible. Thus the additional losses are created in the near hub region as discussed. Increased flow coefficient leads to increased wake size in the near hub region as well and the profile losses (losses due to the boundary layers near the midspan) are not greatly affected.
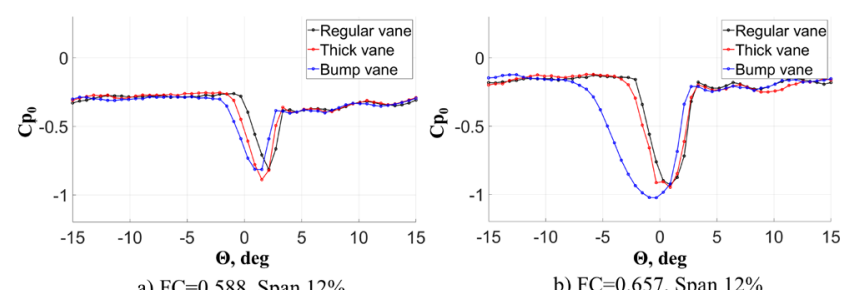

a) $\mathrm{FC}=0.588$, $\operatorname{Span} 12 \%$

b) $\mathrm{FC}=0.657$, Span $12 \%$

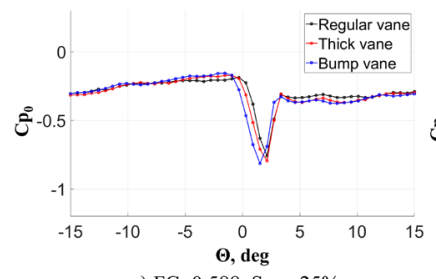

c) $\mathrm{FC}=0.588$, Span $25 \%$
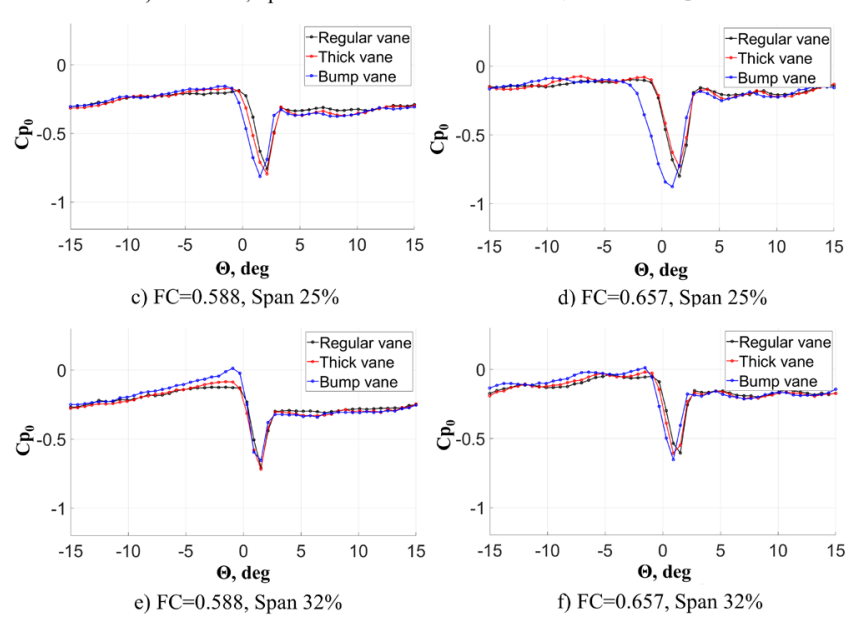

d) $\mathrm{FC}=0.657$, Span $25 \%$

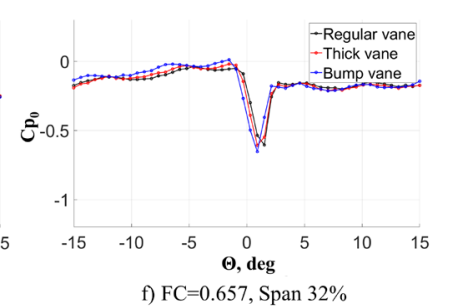

FIGURE 17: Total pressure coefficient distributions for 12, 25 and $32 \%$ spans for the regular, thick and bump vanes at offdesign flow coefficients

\subsection{Initial CFD results}

Initial comparisons with numerical CFD predictions have been done for the regular vane. 3D steady-state CFD simulations were performed of one TRS vane sector using Fluent ${ }^{\mathrm{TM}}$ v19.1. A resolved multi-block structured mesh with $\sim 2$ million cells and $\mathrm{y}^{+}<1$ was created in ICEM Hexa ${ }^{\mathrm{TM}}$. Simulations were performed using the SST k- $\omega$ turbulence model and the LangtryMenter $\gamma-\Theta$ transition model [14]. CFD predictions of the Pressure distributions, as shown in Fig. 9, agree very well with the experimental results. CFD wake profiles are shown in Figure
14 and agree well for the low-load and ADP cases (FC 0.588 and 0.622). In the more loaded case (FC 0.657) CFD predicts a bit too large separation around the $25 \%$ span region. This confirms previous experience that the SST $\mathrm{k}-\omega$ model is a bit conservative in terms of separation predictions. More CFD details, covering also the thick vane and the bump sectors, will be published later in a more comprehensive validation study comparing the experimental results with numerical CFD predictions.

\section{SUMMARY AND CONCLUSIONS}

A detailed experimental aerodynamic study of an enginerealistic turbine rear structure is presented. The experiments were performed at low Mach numbers, but are nonetheless very relevant for engine conditions since in an aero-engine the flow is fully subsonic and there are no compressible effects in the TRS such as shocks or shock-boundary layer interactions.

For the first time the investigated TRS configuration includes three types of OGVs typical for a modern state-of-theart TRS: regular vanes, thickened vanes and vanes with an engine mount recess (a shroud bump). Each of the three OGVtypes were tested under on-design conditions and off-design conditions with a swirl angle varying \pm 5 degrees from the aerodynamic design point.

The flow out of the LPT-stage into the TRS has a radial profile of total pressure and swirl angle. The inlet total pressure increases from the hub to the shroud. The absolute inlet swirl is higher close to the hub and is reduced down to almost axial flow at the shroud. Hence, the OGV loading is larger and the flow momentum is smaller near the hub than near the shroud. The largest pressure losses can be found in a region near the hub on the OGV suction side. The secondary flow from the hub-wall rolls up into a loss-core in the hub-suction side corner. Near the shroud the situation is opposite and the local pressure losses are small. There is, however, a redistribution of the total pressure due to the secondary flow, which brings the high-momentum fluid from the hub to the bulk flow near the OGV suction side. It is not possible to model the presence of the abovementioned radial flow non-uniformity in a linear cascade facility, which makes the current investigation particularly valuable.

As the flow coefficient increases the absolute inlet swirl angle into the TRS increases, as does the OGV load. Increased flow coefficient results in a changed skewing of the inlet total pressure profile. As a result, the inlet swirl near the hub decreases and the OGV loading and the flow deceleration near the hub increase, resulting in increased total pressure losses. A local flow separation is created on the OGV suction side near the hub when the flow coefficient exceeds a certain limit. The flow separation results in a substantial local increase of the total pressure losses. The studied regular vane geometry is shown to handle the inlet swirl variation by \pm 5 degrees without any substantial loss increase in the near-hub region.

A thickened vane (so called tube vane) is shown to have a similar aerodynamic performance as the regular vane. The increased vane thickness results in increased blockage and an increased suction-side diffusion and changed skewing of the inlet total pressure profile without affecting the inlet swirl profile. 
However, despite the substantially increased OGV load on the thickened OGV and increased flow deceleration on the OGV suction side the thickened OGV is shown to handle the on-design and off-design conditions without a substantial increase of the total pressure loss and without loss of the turning performance. The oil-flow visualization at flow coefficient 0.657 has revealed a small flow separation on the OGV suction side near the hub and a small laminar separation bubble with reattachment near the suction side peak, however, these two flow separations were observed on a regular vane as well. A minor loss increase near the hub is observed and the vane profile loss (a 2D loss at midspan) did not change as compared to the regular vane, which showed a good vane design. It can be noted, however, that the thickened vane can potentially have an upstream influence on the LPT by locally affecting the upstream static pressure.

An engine mount recess (a shroud bump) is shown to affect the OGV aerodynamics more substantially. A shroud bump is a structural enforcement of the TRS shroud, which protrudes into the TRS gas path. The bump is shown to have a strong local effect on the OGV wall pressure distribution near the shroud which gradually decreases toward the hub. The current bump design did not reveal any flow separation on the bump itself under on- and off-design conditions. However, the bump is found to affect the OGV aerodynamics indirectly by influencing the inlet conditions into the TRS (the total pressure and swirl profiles) and by increasing the losses in the near-hub region of the OGV. The profile loss at the OGV mid-span is not affected, while a substantial loss increase near the hub (more than double) under on- and off-design conditions is observed. It is notably that the bump influences the OGV losses not only due to the change of the OGV static; the upstream influence on the inlet conditions plays an important role as well. For the vanes under current study, the bump effect on the OGV static pressure in the hub region is less than the effect from the vane thickening, though the losses for the bump are larger. The upstream influence of the bump on the LPT outlet conditions leads to an absolute swirl increase by approximately one degree and to a changed radial gradient of the total pressure profile. The influence of the bump on the TRS outlet flow, apart from the increased losses, leads a notable flow over-turning in the shroud region and under-turning in the hub region, where separation occurs.

\section{ACKNOWLEDGEMENTS}

The authors would like to thank Isak Jonsson for the regular vane data presented in this work and for supporting current experiments. The financial support from the Nationella flygtekniska forskningsprogrammet and the EU-commission is highly appreciated. Chalmers Laboratory of Fluids and Thermal Sciences is acknowledged for hosting the facility and for the measurement equipment.

\section{REFERENCES}

[1] Hjärne, J., Larsson, J., Löfdahl, L. "Performance and Off-Design Characteristics for Low Pressure Turbine Outlet Guide Vanes: Measurements and Calculations" in Proc. of ASME Turbo Expo 2006, Paper GT2006-90550.
[2] Hjärne, J., Larsson, J, Löfdahl, L. “Design of a Modern Test Facility for LPT/OGV Flows" in Proc. of ASME Turbo Expo 2003, Paper GT2003-38083.

[3] Hjärne, J., Chernoray, V., Larsson, J, Löfdahl, L. "Experimental Evaluation of the Flow Field in a State-of-the-Art Linear Cascade with Boundary Layer Suction" in Proc. of ASME Turbo Expo 2005, Paper GT2005-68399.

[4] Hjärne, J., Chernoray, V., Larsson, J., Löfdahl, L. “An Experimental Investigation of Secondary Flows and Loss Development Downstream of a Highly Loaded Low Pressure Turbine Outlet Guide Vane Cascade" in Proc. of ASME Turbo Expo 2006, Paper GT2006-90561.

[5] Hjärne, J., Chernoray, V., Larsson, J., Löfdahl, L. "Numerical Validations of Secondary Flows and Loss Development Downstream of a Highly Loaded Low Pressure Turbine Outlet Guide Vane Cascade", in Proc. of ASME Turbo Expo 2007, Paper GT2007-27712.

[6] Selic, T., Lengani, D., Marn, A., and Heitmeir, F. "Aerodynamic Effects of an Unshrouded Low Pressure Turbine on a Low Aspect Ratio Exit Guide Vane", in Proc of ASME Turbo Expo 2012, Paper No GT2012-68981.

[7] Rojo, B., Kristmundsson, D., Chernoray, V., Arroyo C., Larsson J. "Facility for Investigating the Flow in a Low Pressure Turbine Exit Structure" in Proc of 11th European Conference on Turbomachinery Fluid Dynamics and Thermodynamics, ETC 2015.

[8] Jonsson, I., Chernoray, V., Dhanasegaran, R. "Infrared Thermography Investigation of Heat Transfer on Outlet Guide Vanes in an Engine Exit Module" in Proc. of 13th European Turbomachinery Conference on Turbomachinery Fluid Dynamics and Thermodynamics, ETC 2019.

[9] Jonsson, I, Chernoray, V., Rojo, B., "Surface Roughness Impact on Secondary Flow and Losses in a Turbine Exhaust Casing" in Proc. of ASME Turbo Expo 2018, Paper GT201875541 .

[10] Jonsson, I., Deshpande, S., Chernoray, V., Thulin, O., Larsson, J., "Experimental and Numerical Study of LaminarTurbulent Transition on a Low-Pressure Turbine Outlet Guide Vane", in Proc of ASME Turbo Expo 2020, Paper GT2020-1787.

[11] Hjärne, J., Chernoray, V., Larsson, J. "Experimental Investigations and Numerical Validation of an Outlet Guide Vane with an Engine Mount Recess" in Proc of ASME Turbo Expo 2008, Paper GT2008-50168.

[12] Arroyo, C. "Aerothermal Investigation of an Intermediate Turbine Duct", PhD Thesis, Chalmers University of Technology, Gothenburg, Sweden, 2009.

[13] Hjärne, J. "Turbine Outlet Guide Vane Flows", PhD Thesis, Chalmers University of Technology, Gothenburg, Sweden, 2007

[14] Menter, F. R., R. B. Langtry R.B., Likki S.R., Suzen Y. B., Huang P.G., Völker S. "A Correlation-Based Transition Model Using Local Variables-Part I: Model Formulation". Journal of Turbomachinery, 128(3), 03, pp. 413-422. 